可視化情報 Vol.19 Suppl. No1（1999 年 7月）

\title{
$228 \mathrm{~d}$ 形粗面境界層における乱れ生成機構と抵抗低減
}

\author{
望月信介○、大坂英雄（山口大工）
}

\author{
Turbulent Production Mechanism and Drag Reduction \\ in a d-Type Rough Wall Boundary Layer
}

\author{
Shinsuke Mochizuki and Hideo Osaka
}

\begin{abstract}
Based on a model for momentum transport and turbulence production near the wall by means of unsteady streamwise vortex, a turbulence control technique with longitudinal thin ribs were proposed for d-type rough wall boundary layer and an experiment with direct skin-friction measurement confirmed its efficiency for turbulent drag reduction. The maximum reduction rates of local skin friction coefficient compared with the original d-type rough wall flow and a smooth wall flows are about $10 \%$ and $3 \%$, respectively. Examination of the turbulent intensity and Reynolds shear stress profiles shows that the vortex model assumed for the present control technique is reasonable. The streaky structure was observed near the wall and effect of the longitudinal thin ribs on the probability density distribution of the spanwise spacing $\lambda_{z}$ was investigated.
\end{abstract}

Keywords: Drag Reduction, d-Type Roughness, Coherent Structure, Hairpin Eddy

\section{1. 緒 論}

本研究の目的は、組織構造に基づく乱れ生成機構の一 モデルに従い、粗面溝内部に流れ方向リブ（以下、縦リ ブと呼ぶ）を㨂入し、 $\mathrm{d}$ 形粗面境界層の抵抗低減を図る ことである。

リブレットは壁面せん断乱流に対するパッシーブな抵 抗低减法として盛んに研究され、その有效性か内内部流お よび外部流において確認されている(1)。その抵抗低減入 カニズムの解明についてみると、壁領域における乱れ生 成機構に対するバースティングや縦洞構造といった整構 造（Coherent structure）との関係が議論されている(1)。 しかしながら、外部流においては直接測定による壁面せ

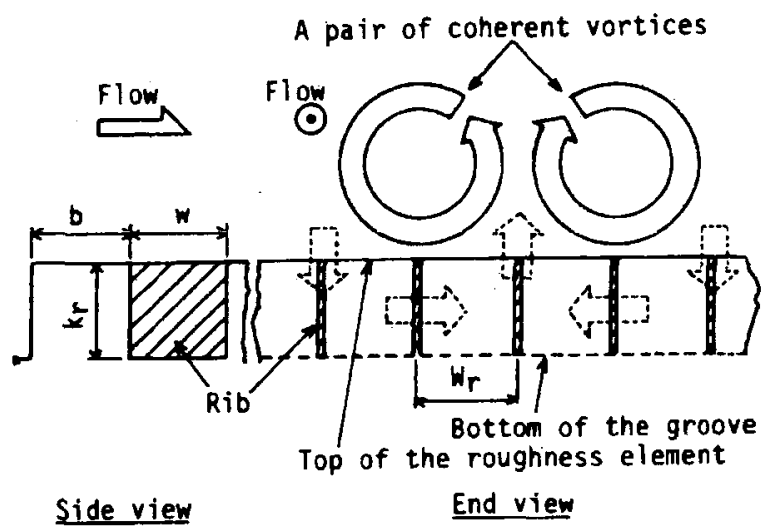

Fig.1 A model of momentum transports by means of unsteady streamwise vortex near the d-type roughness.
ん断応力の值に基づく実験例がほとんどないことや、整 構造の定義においても多くの課題が残されているため、 抵抗低減义カニズムと整構造との関係について一致した 結論は得られていない。

条件付解析等に基づき推測された d 形粗面上における 非定常縦渦構造 ${ }^{(2)}$ とそれによる運動量輸送および乱れ 生成機構を図 1 に示す。非定常縦渦構造は Common-flow up の渦対形状をなし、これらは滑面上で提案されている ようなへアピン渦の根幹部に相当するものと推測される。 この縦渦対はその誘導速度により、溝内部におけるスパ ン方向輸送および溝内部と境界層との運動量交換を促進 するものと考えられる。溝内部から放出された低運動量 の流体塊は縦渦対により生成される高せん断層を強め、 バースティングによる乱れ生成を増加させるものと予想 される。そこで、溝内部に適当なスパン方向間隔で仕切

（縦リブ）を挿入すると、縦渦構造を介した溝内部と境 界層との干涉により促進された運動量交換および乱れ生 成率が抑制され、抵抗低減が生じるものと期待される。

本報告においては、縦リブによる $\mathrm{d}$ 形粗面境界層の抵 抗低減制御を実験的に試み、壁面せん断応力の直接測定 および時間平均量分布の測定からその有効性を確認する。 2. 実験装置および方法

$\mathrm{d}$ 形粗面平板は、粗さ要素高さ $\mathrm{kr}$ 、要素幅 $\mathrm{b}$ および淟 部幅 $\mathrm{w}$ がいずれも $3 \mathrm{~mm}$ の矩形粗さの配列からなる。縦 リブは厚さ $0.1 \mathrm{~mm}$ の銅板製で、流れ方向 $305 \mathrm{~mm}$ および 


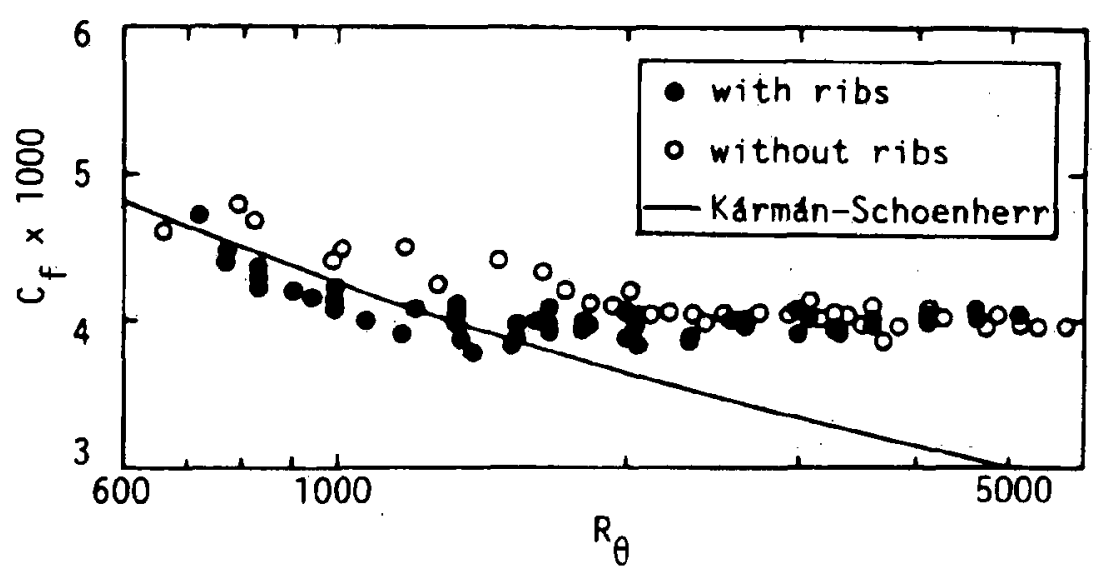

Fig.2 Local skin friction coefficient as a function of momentum thickness Reynolds number.

スパン方向 $150 \mathrm{~mm}$ の範囲にスパン方向間隔 $\mathrm{Wr}=3 \mathrm{~mm}$ 一 定で溝内部に設置された。この縦りブを挿入した平板を 十分発達した $\mathrm{d}$ 形粗面境界層が形成された位置（平板前 縁から測つた距離が $x_{0}=800 \mathrm{~mm}$ および $1800 \mathrm{~mm}$ の 2 条件) に設置した。実験は零圧力勾配および主流乱れ強さ $0.3 \%$ の下で行われた。

局所壁面せん断応力の測定は、直径 $60 \mathrm{~mm}$ の浮動片要 素をもつ直接測定装置 ${ }^{(3)}$ により行われた。測定值は差 動トランスデューサからの変位出力の平均値 (20 秒間) と較正式から算出された。速度成分の計測は定温度型熱 線流速計、および直径 $5 \mu \mathrm{m}$ で受感部長さ $1 \mathrm{~mm}$ のタング ステン細線をセンサとするI形および X 形熱線プローブ を用いた。測定は、縦リブ挿入開始位置の下流 $225 \mathrm{~mm}$ の位置において行われた。この発達距離は初期境界層厚 さ $\delta_{0}$ (緹りブ挿入平板設置位置における境界層厚さ）の 11 倍 ( $x_{0}=800 \mathrm{~mm}$ の場合) および 5.6 倍 ( $x_{0}=1800 \mathrm{~mm}$ の 場合）に相当し、粘性長さに対しては 2000 倍以上になる。

\section{3.結果および考察}

3.1 局所壁面せん断応力 図 2 は局所壁面摩擦抵抗係 数 $C_{f} \equiv \tau_{w} /\left(\rho U_{1}^{2} / 2\right) \quad\left[U_{1}\right.$ は主流速度、 $\tau_{w}$ は壁面せん断 応力]の運動量厚さ $\theta$ に基ゔくレイノルズ数 $R_{\theta} \equiv \theta U_{1} / \nu$ に対する変化を示す。図中には滑面境界層 の值として、Kármán-Schoenherr の実験式 ${ }^{(4)}$ を実線で示 した。縱りブ挿入平板上の $C_{f}$ は $R_{\theta}>2000$ においては d 形粗面上の值と同程度で、滑面流の值に比べ大きい。一 方 $R_{\theta} \leq 2000$ においては、繸リブ挿入平板上のC $C_{f}$ はd形 粗面上の值よりも低く、抵抗低減が生じていることがわ かる。また、 $750<R_{\theta}<1200$ の範囲において縦りブ挿入平 板上の $C_{f}$ は滑面流のものよりも小さい。これらは緃りブ が $\mathrm{d}$ 形粗面境界層の抵抗低隇に対して有効であり、かつ 滑面流よりも局所摩擦抵抗係数が低い粗面平板を実現し た極めて重要な結果である。滑面流および d 形粗面流に 対する $C_{f}$ 值の低減率における最大值は、それぞれ $10 \%$ $\left(R_{\theta}=1200 \sim 1300\right)$ および 3\% $\left(R_{\theta}=1000\right)$ であった。

ここでは縦渦構造による運動量輸送および乱れ生成機
構に対して仮定したモデルの妥当性をみてみる。図 3 は 抵抗低減率 $\Delta C_{f d} \equiv\left(C_{f R}-C_{f d}\right) / C_{f d} \times 100(\%)\left[C_{p R}\right.$ は縦り ブ挿入平板、 $C_{f a}$ は d 形粗面平板上の $C_{f}$ である]をリブ レイノルズ数 $W_{r}^{+} \equiv W r u_{\tau} / v\left[u_{\tau}\right.$ は摩擦速度 $]$ に対して示 す。リブレイノルズ数は縦リブスパン方向間隔 $W r$ の縦 渦構造の代表尺度 $v / u_{\tau}$ に対する比として解釈できる。縦 渦構造のスパン方向代表寸法は後述のように粘性長さの 100 倍のオーダーであるため、 $W_{r}^{+} \leq 100$ の範囲において 抵抗低減が期待される。図中には $x_{0}$ に関して 2 筒所の結 果が示され、影付の範囲はデータのばらつきを表してい る。 $R_{\theta}$ 数の差異によらず（ $x_{0}$ によらず）、 $W_{r}^{+} \leq 100$ にお いて抵抗の低滅が生じている。このことより、縦リブを 用いた d 形粗面境界層の抵抗低減法において仮定された 非定常縦渦構造による運動量輸送モテルは妥当といえる。 しかしながら、低減率の大きさは $R_{\theta}$ 数により異なってお り、最大の低隇率が得られる $W_{r}^{+}$の值は不明である。

\section{2 時間平均量分布 平均速度、乱れ強さおよびレイ} ノルズせん断応力分布に与える縦リブ挿入の影響をみて みる。図 4 は抵抗低減がみられたレイノルズ数範囲にお ける対数速度分布を示す。壁面に垂直方向の距離は直接 測定によるC $C_{f}$ に基づき Monin-Yaglom 法 (5) から原点補 正量 $\varepsilon$ を求め、 $y=y_{t}+\varepsilon$ とした。図中には 1968 年の Stanford 会議において提案された滑面流に対する対数速 度分布 ${ }^{(4)}$ を実線で描いた。結果をみると、傾きは実線

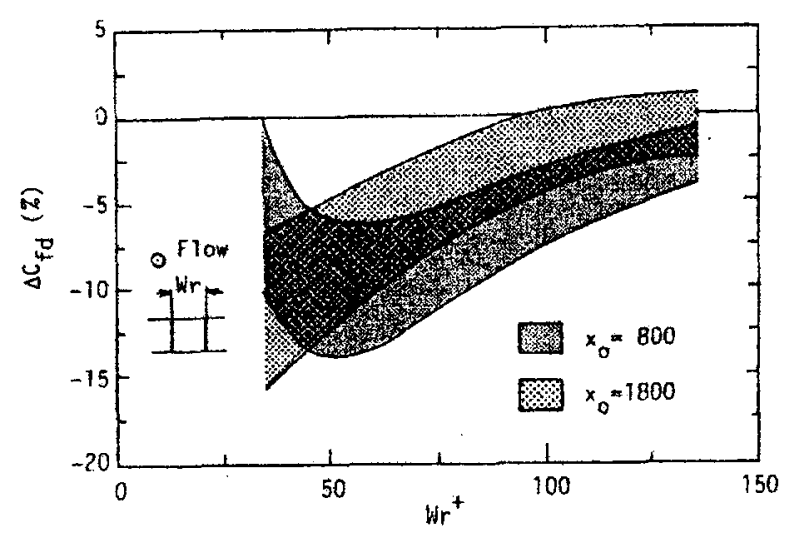

Fig.3 Reduction rate of local skin friction coefficient. 
で示す滑面流の対数速度分布のものとほぼ同じ（したか って、カルマン定数 $\kappa=0.41 ）$ 対数直線部がみられるもの の、切片の值に差異がみられる。 $C_{f}$ 值が滑面流とほぼ

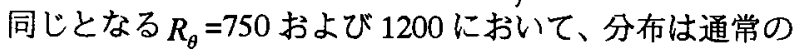
対数速度分布に一致する。一方、 $C_{f}$ 值が滑面流よりも 低い $R_{\theta}=860$ および 910 においては、分布は通常の対数 速度分布よりも上方にある。したがって、粗面流におい て通常は抵抗の増加を表現する粗さ関数は負の值をとる ことになる。これは、リブレット(1) および LEBU によ る抵抗低隇の場合にもみられている。このことは、対数 層の存在を認めると、抵抗低減によるエネルギ散逸率の 減少にともなう最小渦寸法あるいは粘性底層の厚みの増 加と解釈される。滑面流に比べ $C_{f}$ 值が大きい $R_{\theta}=1570$ の場合、分布は通常の対数速度分布の下方に位置する。

図 5 は粗さ関数を $\mathrm{d}$ 形粗面の代表粗さ寸法である原点 補正量に基づくレイノルズ数 $u_{\tau} \varepsilon / v$ に対して描いたもの である。本結果は抵抗低隇が生じていることおよび低レ イノルス数の範囲であるため、実線で示す高レイノルズ 数のものよりも上方に位置している。注目すべき結果は、 滑面よりも抵抗係数が低い条件においては粗さ関数およ

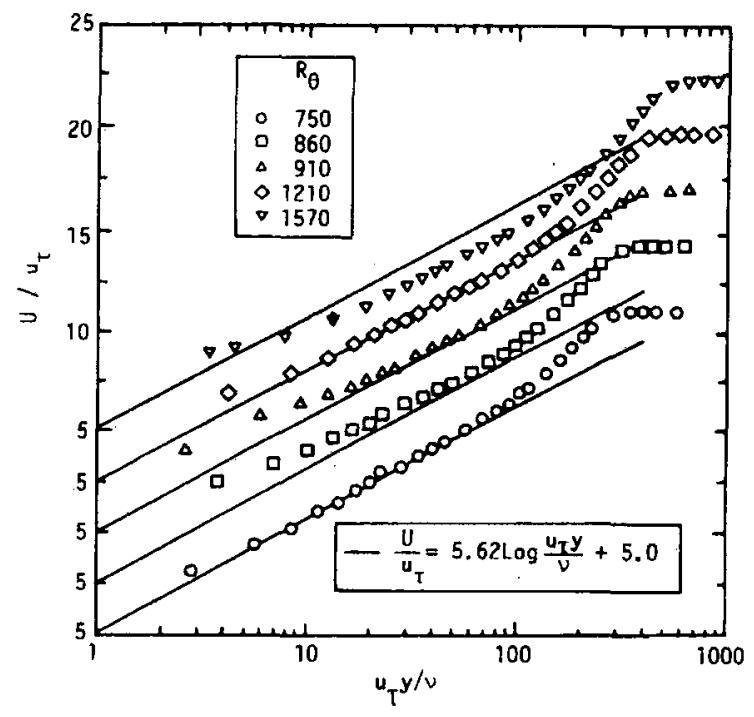

Fig.4 Logarithmic velocity profiles.

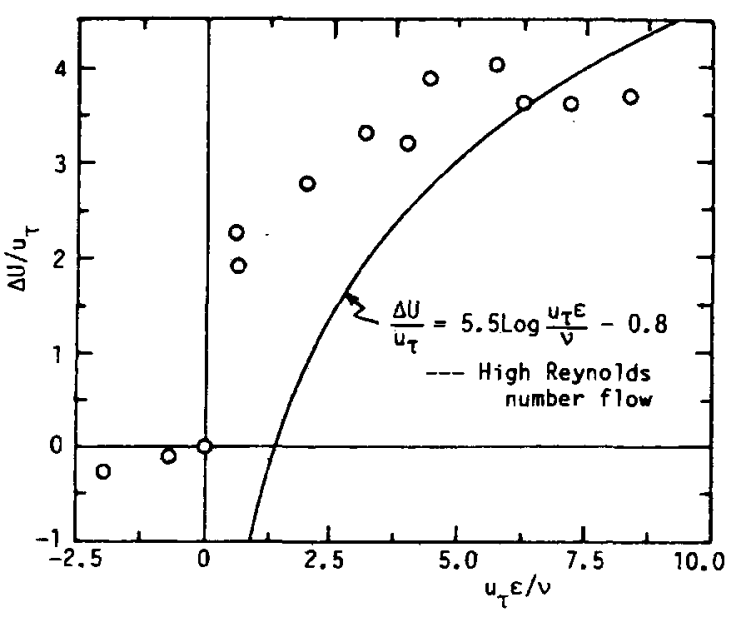

Fig.5 Roughness function.
び $u_{\tau} \varepsilon / v$ 值の両者が負の値をとっていることである。 $u_{\tau} \varepsilon / v<0$ の值については、原点補正量 $\varepsilon$ が負の值をとる ことによるもので、相似性成立のための仮想原点が粗さ 要素頂上よりも上方に位置することになる。このことは、 縦渦構造をエネルギ含有渦とすると、その代表寸法 $\ell$ お よび乱流レイノルズ数 $u \ell / v$ の堿少を意味するものと考 えられ、前述の最小渦寸法の増加と対応する。

乱れ生成機構に対する影響をみるため、流れ方向乱れ 強さ分布の変化をみてみる。図6においては、縦少フ挿 入により抵抗低減の生じた条件 $R_{\theta}=1300\left(W_{r}^{+}=35\right)$ およ び抵抗低減が生じなかった条件 $R_{\theta}=5000\left(W_{r}^{+}=120\right)$ に おける 2 つの代表的な結果を示す。抵抗低減が生じた $R_{\theta}=1300\left(W_{r}^{+}=35\right)$ の場合、壁近傍において $u_{r m s} / U_{1}$ 值 の減少が確認され、d 形粗面流に対する最大の低減率は 測定した範囲で 45\%である。この $u_{r m s} / U_{1}$ 值の減少は、 抵抗低減の生じなかった $R_{\theta}=5000\left(W_{r}^{+}=120\right)$ において も確認される。 $u_{r m s} / U_{1}$ 值の減少は、内層 $y_{t} / \delta<0.2$ の範 囲で認められる。したがって、縦リブによる $\mathrm{d}$ 形粗面平 板の変更は、そのほとんどが生成される壁近傍の乱れ生

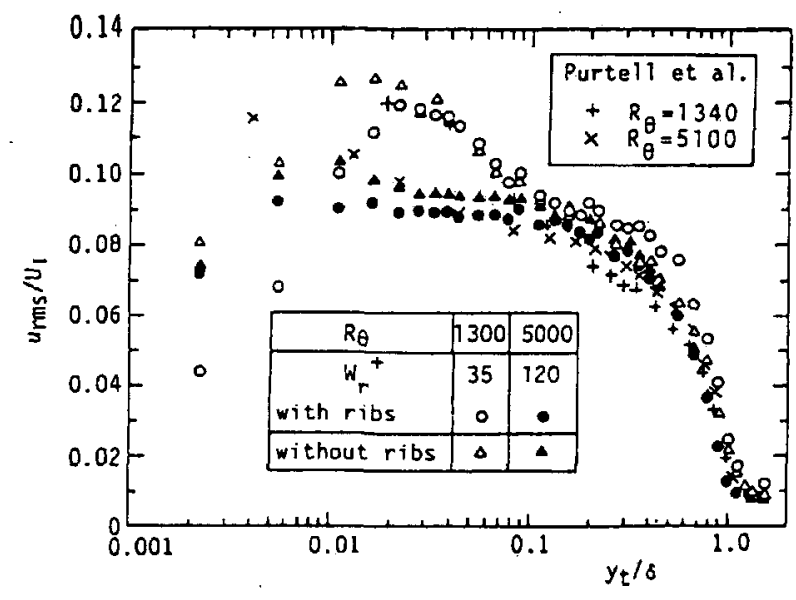

Fig.6 Modification in streamwise turbulent intensity profiles.

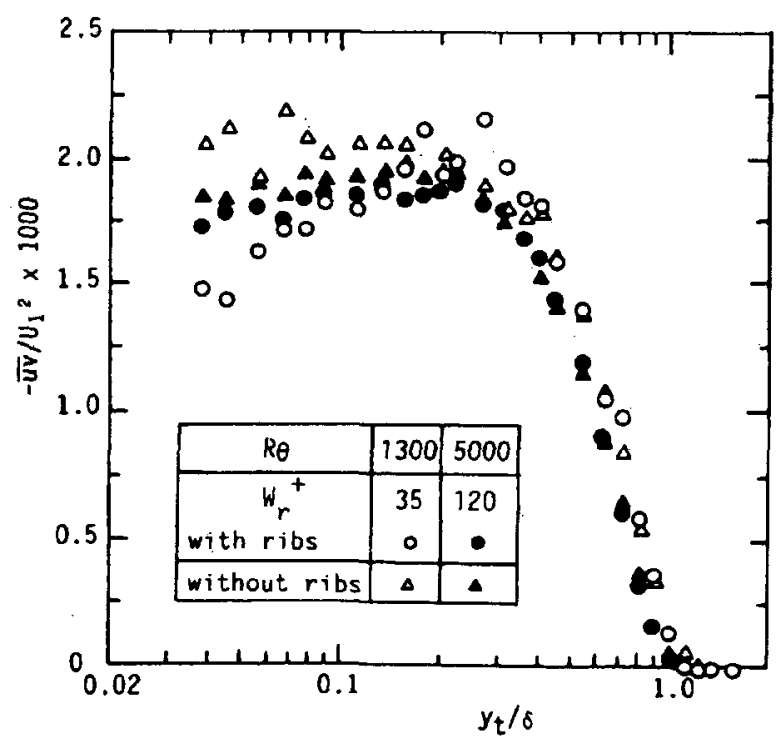

Fig.7 Modification in Reynolds shear stress profiles. 
成率を減少させていることがわかる。このことは、本抵 抗低減法提案の基礎となった縱渦構造か、、溝内部と境界 層との運動量交換と乱れ生成機構の両者に関連すること を示す証拠の一つであると考えられる。滑面流よりも $C_{f}$ 值が大きい $R_{\theta}=1300$ において $u_{r m s} / U_{1}$ 值は Purtell ら の滑面流のもの ${ }^{(6)}$ に比べ大きい。

図 7 はレイノルスせん断応力分布を示す。縦リブ㨂入 により抵抗低減の生じた $R_{\theta}=1300\left(W_{r}^{+}=35\right)$ において、 壁近傍におけるレイノルスせん断応力 $-\overline{u v} / U_{1}^{2}$ 值が減 少し、壁面方向に向かう運動量流束が抑制されたことを 明かに示している。一方、縦リブ挿入により抵抗低減の

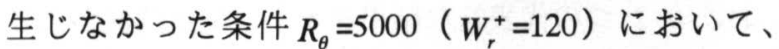
$-\overline{u v} / U_{1}^{2}$ 值の減少はみられない。なお、 $R_{\theta}=1300$ $\left(W_{r}^{+}=35\right)$ における壁領域において $-\overline{u v} / u_{\tau}^{2} \approx 1$ となる 領域が存在していた。そのことは、縦リブの㨂入により 抵抗低減の生じた流れ場においても対数速度分布成立の 妥当性を支持する一定応力層を仮定が適用可能であるこ とを意味している。

\section{3 ストリーク構造の可視化}

滑面流において乱れ生成機構と密接に関連することが

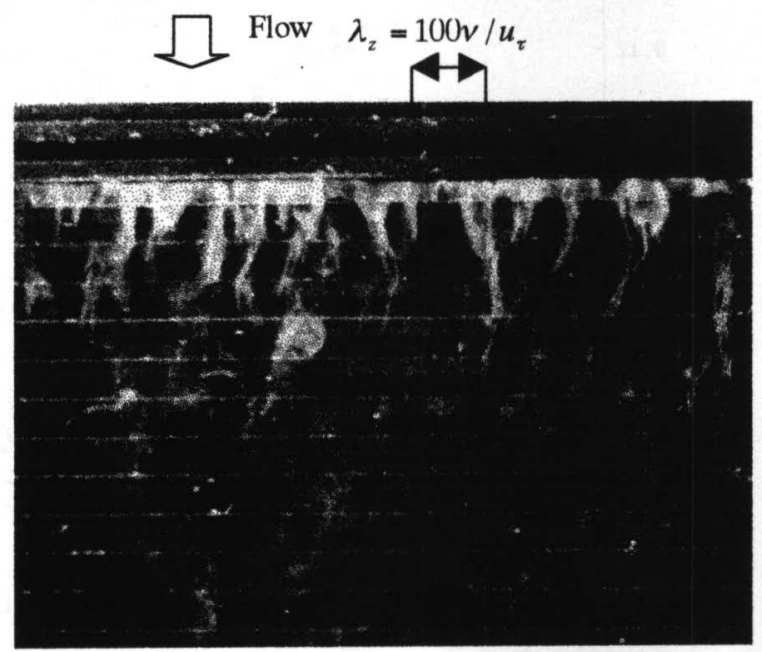

Fig. 8 Streaks over the d-type rough surface at $R_{\theta}=1300$.

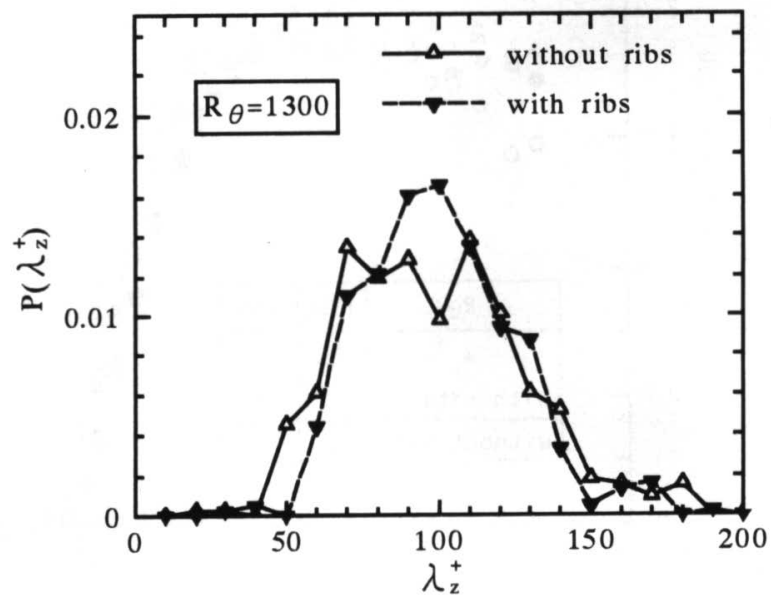

Fig.9 Probability density distribution of spanwise spacing of the streaks and its modification due to the longitudinal ribs.
示唆されているストリーク構造の可視化を行った。図 8 は $R_{\theta}=1300 （ W_{r}^{+}=35 ）$ の $\mathrm{d}$ 形粗面上における上方から撮 影した写真である。トレーサーには灯油による煙を用い、 これを溝底部に設けたスリットからスパン方向に一様に 放出した。この際の放出流量は境界層中における流量の 1/10,000 以下であった。滑面上においてみられる縞模様 が d 形粗面上においてもみられる。このことは d 形粗面 上における乱れ生成機構が滑面流と類似の構造をもつこ とを示唆しており、d 形粗面流が擬滑面流と呼ばれるこ とを説明する証拠でもある。図 9 は、およそ 360 個の標 本から求めたストリーク構造のスパン方向間隔 $\lambda_{2}$ の粘 性長さに対する比 $\lambda_{z}^{+} \equiv \lambda_{z} u_{\tau} / v$ の確率密度分布図である。 $\lambda_{2}^{+}$は 50 150 の範囲に分布している。縦リブ挿入により 比較的小さい間隔の事象の発生頻度が減少したため、そ の平均值は $\lambda_{z}^{+}=98$ から 100 へと増加した。また、標準偏 差の值は縦リブ㨂入により 29.5 から 24.5 と減少してい る。ストリーク構造は図 1 で示した縦洞構造の中央にお いて、溝内部の流体塊を境界層内に吸引することにより 発生すると考えられる。また、これら縦渦構造か $x$ - $z$ 平 面内に密に存在しないため、 $\lambda_{z}$ が直接に縱渦構造の横断 面寸法を与えるとは考えがたい。一方、抵抗低隇により 縦渦構造およびそれに関連する高せん断層の強度が弱ま り、バースティングの発生周波数が減少することが予想 される。それにともない、比較的小さいスパン方向間隔 $\left(\lambda_{z}^{+}=50\right.$ 付近）のストリーク構造の発生が減少し、結果 として $\lambda_{z}^{+}$の平均值が増加したと考えることができる。

4. 結 論

1）直接測定による壁面せん断応力測定により、縦リブ による $\mathrm{d}$ 形粗面境界層の抵抗低減に有効であること が示された。最大低隇率は、d 形粗面流に対し $10 \%$ 、 滑面流に対し $3 \%$ あった。

2）抵抗低減によらず滑面流のものと同じ傾き（カルマ ン定数 $\kappa=0.41 ）$ の対数直線部は存在するものの、切 片の值は異なる。

3）乱れ強さおよびレイノルスせん断応力の值は、抵抗 低隇の生じた条件の内層において隇少した。

4) 抵抗低減率および乱れ強さ分布の解析から、仮定し た縱渦構造による運動量輸送および乱れ生成機構の 妥当性が示された。

文 献

1) Walsh,M.J.,Riblets:Viscous Drag Reduction in Boundary Layer(ed.Bushnell,D.M.\&Hefner,J.N)., 1990, pp.203-262.

2) 大坂英雄, 望月信介, 低レイノルズ数における d 形粗 面乱流境界層の縦渦構造 : 日本機械学会論文集 B 編, 58-486 (1987), pp.371-379.

3) 望月信介, 大坂英雄, 壁面せん断応力の直接測定 : 機 械の研究, 養堅堂, 45(1993)、pp.66-72.

4) 中村育雄, 大坂英雄, 工科系流体力学:共立出版, (1985).

5) Monin,A.S., Yaglom,A.M., Statistical Fluid Mechanics: The MIT Press, (1987), pp.284-295.

6) Purtell,L.P. et al., Turbulent boundary layer at low Reynolds number: Phys.Fluids, 24(1981), pp.802-811. 